\title{
Cardiovascular risks in active athletes within the provincial directorate of youth and sports: a descriptive cross-sectional study
}

\author{
HASAN SAKALLI ${ }^{1}$, CELAL KUŞ ${ }^{1}$, RAZIYE GÜMÜŞTAKIM², Duygu AYHAN BASER ${ }^{3}$, \\ AHMET ÇAĞRI AYKAN ${ }^{2}$, and SELÇUK AKTURAN ${ }^{1}$
}

${ }^{1}$ Affiliation not available

${ }^{2}$ Kahramanmaras Sutcu Imam University - Avsar Campus

${ }^{3}$ Hacettepe University Faculty of Medicine

July 23, 2020

\begin{abstract}
Background: The place of sport is indisputable for a healthy society. This study aimed to assess the health risks of athletes engaged in sports activities in various branches in the Youth Center operating. Methods: In this cross-sectional study, data from 181 athletes were analyzed. A 20-item questionnaire including demographic information and sports history of the athletes was applied to the participants. Physical examinations were performed. Additionally, complete blood count, biochemistry, lipid profile, TSH, T4, and ECG examinations were requested from the participants. Results: In 25 (13.8\%) of the participants, a pathology that could constitute a sport obstacle was detected. When the data examined concerning the presence of pathological status were compared, cardiac rate, HDL, LDL, calcium, ALT, diastolic blood pressure, the frequency of training per week, the presence of ventricular hypertrophy, $\mathrm{t}$ wave, and deviation in cardiac axis were statistically significant. Conclusion: The presence of conditions that may pose a risk to the health of athletes in people who are engaged in active sports suggests that some findings have been missed in the examinations for entry to sports. Family physicians should take a full anamnesis when evaluating people who want to do sports, carry out a detailed examination, and predicate their findings on laboratory findings.
\end{abstract}

\section{What's already known about this topic?}

- Various screening and risk classification tools are used before participation in sports activities.

- The use of cardiovascular risk scores to determine a person's 10-year risk of cardiovascular disease has been widely accepted and varies from country to country (Systematic Coronary Risk Evaluation, Framingham Risk Score, etc.).

- This has led to the emergence of different pre-sport screening recommendations and different protocols.

\section{What does this article add?}

- Although screening tests do not fully capture diseases, they are very helpful in identifying those who can perform sports.

- Laboratory and ECG can be used to increase the sensitivity in sports examinations.

- Family medicine practice can provide a significant advantage in terms of cost effectiveness.

\section{INTRODUCTION}

In recent years, the number of young and adult sport professionals has been increasing. Sport is considered to be a useful activity in the physical and mental development of individuals due to its positive contribution to the continuation of health status, prevention of obesity and diseases that may develop due to sedentary life and to the person's social life. ${ }^{1,2}$ Regular exercise has proven to be an effective method to prevent obesity ${ }^{3}$, 
cardiovascular diseases ${ }^{1}$, diabetes, breast ${ }^{4}$, colon, rectal ${ }^{5}$ and prostate ${ }^{6}$ cancers. ${ }^{7}$ Physical activity is known to reduce depression ${ }^{8}$, lower blood pressure ${ }^{9}$, positively affect bone health ${ }^{10}$, improve symptoms in fibromyalgia patients $^{11}$, and reduce the risk of dementia. ${ }^{12}$

Although the benefits of exercise for staying healthy are undeniable, it is a fact that it brings some risks. Loading the organism above a certain level can trigger unexpected cardiac deaths. ${ }^{13}$ The underlying silent pathologies are usually responsible for such events. ${ }^{14}$ Although the incidence of sudden cardiac death (SCD) during sports and exercise activities is difficult to pinpoint, the generally accepted rate is 1-3 per 100 $000 .{ }^{15}$ However, although not very high, unexpected sudden deaths cause deep sorrow and anxiety in the community and family members. It is possible to identify most of these sudden deaths by pre-accession health assessments. On the other hand, exercise overloads can also cause musculoskeletal injuries. The importance of these evaluations in determining and monitoring these cannot be denied.

Health fitness report for sports are organized by family physicians, sports physicians and cardiologists in Turkey. This necessitates a systematic approach for physicians beyond being a legal and professional responsibility.

Various screening and risk classification tools are used before participation in sports activities. Leading institutions such as the American Heart Association (AHA), the American College of Sports Medicine (ACSM), and the American Society of Cardiovascular and Pulmonary Rehabilitation (AACVPR) have developed important screening recommendations for the general population. Screening and risk classification prior to participation in sports or physical education activities is accepted as a standard practice. In the 'Physical Activity Reading Questionnaire for All (PAR-Q +)' and 'Electronic Physical Activity Preparedness Questionnaire' (ePARmed-X + ) developed for this purpose, the barriers to physical activities have been greatly reduced, and it has led to an increase in participation in physical activities for apparently healthy individuals and people with chronic health problems.

Medical report is required only for sports licenses in Turkey. However, like many reports, a health report is sometimes considered a formality. Therefore, some families and sports clubs do not give the necessary importance to the health control of the athletes. Family doctors have great responsibility in this regard. If the family physician approves the medical report, he or she takes full legal responsibility. Unfortunately, there is no guide or form available to family physicians prior to physical education activities. The effectiveness of the evaluations made before the sporting activities is also discussed.

\section{Purpose}

The aim of this study is to make cardiovascular risk assessments of athletes engaged in sports activities in various branches in the Youth Center operating within Provincial Directorate of Youth and Sports and to reveal the importance of laboratory studies such as ECG and lipid profile before sport activities.

\section{METHODS}

This research was conducted as a descriptive cross-sectional study. The reporting of the study was carried out in accordance with the STROBE criteria. ${ }^{16}$ At the same time, approval was obtained from the Academic Board of the medical faculty of a university (Date: 06.02.2019, issue: 08).

The athletes who accepted to participate in the study were invited to Family Medicine Polyclinic of the medical faculty of a university. A 20-item questionnaire including the stories of the athletes was prepared by scanning the literature was conducted to participants between November 2018 and April 2019. The questionnaire was completed by face to face interview method in the family medicine policlinic. Anthropometric measurements were taken by the researcher, physical examinations were performed and the findings were recorded on cardiovascular risk screening form in athletes. Hemogram, biochemistry and ECG examinations of the participants were also requested. The ECGs of the athletes were analyzed by the cardiologist and the 
findings were recorded on the same screening form. Athletes with pathological findings were referred to the relevant departments.

The population of the research consisted of 4400 athletes operating in Kahramanmaraş Provincial Directorate of Youth and Sports. From the list received from the Directorate, 200 of these athletes were identified using a table of random numbers and they were sent a written invitation to participate in the research. A total of 181 people agreed to participate in the study and the data of all participants were analyzed; there was no data loss (Figure 1).

The inclusion criteria of the study were determined to be active in moderate and heavy sports activities at least 3 days a week and at least 1 hour regularly with the coaches of Kahramanmaraş youth and sports provincial directorate and to be between the ages of 6-65.

The sample calculation was based on the presence of any pathology that could prevent sports in athletes. In a sample of 4400 individuals with a population of 179 , an estimated $14 \%$ prevalence is required to determine the $5 \%$ error margin and $95 \%$ confidence interval ${ }^{17}$. Considering data loss and the possibility of rejecting the invitation, the sample of the study was determined as 200 people.

The dependent variable of the study is whether there is a pathology that may pose a risk for sports in physical examination, laboratory and ECG examinations. Other variables; dizziness, blackout, fainting, chest pain or shortness of breath during or after exercise, fatigue before friends, heart rate different or faster than normal when resting, high blood pressure and high cholesterol levels, heart murmur in the family before the age of 50 , death due to heart disease, family history of sudden death of unknown cause at a young age, heart-related infectious disease in the last month, having close relatives of SCD, the type of sport performed and how many years of sport.

The body weight of the patients was measured with Tanita SC 30 bioelectrical impedance analyzer and the lengths were measured with a $1 \mathrm{~mm}$ spacing. BMI values were calculated using the following formula using body weight and height.

BMI $(\mathrm{kg} / \mathrm{m} 2)=$ Body Weight $(\mathrm{kg}) /$ Length $(\mathrm{m})^{2}$

Data were entered into the computer and analyzed with SPSS 25.0 program (Chicago, IL, USA). The findings of the study were presented as numbers and percentages for categorical variables and as mean and standard deviation for numerical variables. The suitability of the numerical variables to the normal distribution was evaluated by looking at the skewness and kurtosis coefficients. Comparisons of the groups were made by independent samples t test for parametric test conditions. In cases where parametric test conditions were not met, Mann Witney U test was used. Chi-square test was used in cases where categorical data should be compared. Statistical significance was taken as $\mathrm{p}<0.05$.

\section{RESULTS}

When the data of the participants were examined, it was seen that $148(81.8 \%)$ were male, $33(18.2 \%)$ were female, and the mean age was $21.27 \pm 6.72$ years (10-45 years). None of the participants had been smoking.

The mean \pm SD of QTc (msn), QRS (msn) and PR (msn) were 392.55 $\pm 21.94 ; 85,31 \pm 10,14$ and 133,02 \pm 17,50 , respectively. The mean \pm SD of systolic and diastolic blood pressure were $102.63 \pm 12.07$ and 65.45 \pm 8.30 , respectively. Descriptive statistics of numerical variables are given in Table 1 .

When the distribution of the participants was examined according to their sports branch, it was seen that football was the most preferred branch with $16.6 \%$, followed by volleyball and swimming (Table 2).

As a result of the study, $25(13.8 \%)$ of the participants were identified to be inconvenient in terms of sports. The most common disorders were; triglyceride $(\mathrm{n}=12)$, hemoglobin $(\mathrm{n}=3)$ and TSH $(\mathrm{n}=2)$ elevation. 
ECG revealed left ventricular hypertrophy and T negativity, left axis deviation, right bundle branch block, short PR and delta wave and short QT in one athlete.

When the data were compared in terms of the presence of pathology that may pose a risk to health, a statistically significant difference was found in terms of cardiac rate, HDL, LDL, calcium, ALT, diastolic blood pressure, and the number of training times per week, there was no significant difference in other variables (Table 3 ).

When the categorical variables were compared, a statistically significant difference was found in terms of ventricular hypertrophy, $\mathrm{t}$ wave and deviation in cardiac axis (Table 4).

\section{DİSCUSSION}

When the distribution of the participants was examined according to their sports branch, football was the most preferred branch with $16.6 \%$, followed by volleyball and swimming. When the data were compared in terms of dependent variable, there was a statistically significant difference in terms of cardiac rate, HDL, LDL, calcium, ALT, diastolic blood pressure, and the number of training times per week, there was no significant difference in other variables. When the categorical variables were compared according to the main outcome measures of the participants, a statistically significant difference was found in terms of ventricular hypertrophy, $\mathrm{T}$ wave, and deviation in cardiac axis.

Sudden athlete deaths, injuries during sports and variability in athlete performances have led to the discussion of the examination of athletes. The athletes underwent an evaluation including potential personal health history, family history, history of drug use, physical examination and possible diagnostic tests to identify potential risks for heart disease, musculoskeletal disease, neurological diseases, respiratory disease, bleeding disorders and psychiatric disorders, they kept.

The athletes underwent an evaluation including potential personal health history, family history, history of drug use, physical examination and possible diagnostic tests to identify potential risks for heart disease, musculoskeletal disease, neurological diseases, respiratory disease, bleeding disorders and psychiatric disorders. they kept.

Blood tests and ECG can be used to assess the structure and function of the heart and the health status of the organs. Abnormal findings detected in history, physical examination, blood tests or ECG may lead to further diagnostic tests and evaluations. ${ }^{18}$ In our study, pathology was detected in the light of these findings in $13.8 \%$ of the participants (25 people) and referred to internal medicine, cardiology and pediatric hematology departments for further diagnostic tests and evaluations. However, it was concluded that the pathologies identified as a result of the analyzes did not prevent the participants from doing sports.

An important issue that limits physical examinations before participation in sports is the potential to cause unnecessary tests. ${ }^{19}$ False positive findings in tests may cause unnecessary anxiety in the patient and may lead to further tests. In order to ensure that unnecessary testing and treatment are minimized, it is important for the physician to evaluate each athlete according to his condition. ${ }^{20}$

The fact that there are many interested in football among the participants may be due to the interest in football in our country as well as the fact that it requires more team players compared to other branches. The fact that the number of those who were interested in swimming was relatively high among those who participated in the study suggested that health awareness might be higher among those who preferred this branch.

The use of doping is known to increase hemoglobin levels. ${ }^{21}$ In our study, hemoglobin level was found to be significantly higher in the group with pathology. This increased the suspicion that the higher pathological findings may be due to doping in the group with high number of training sessions per week. In addition, it 
was evaluated that both the intensity of training and the desire to use doping may be higher in individuals with high ambition to win.

An important reason for pre-accession screening in athletes is the effort to prevent sudden deaths. The main cardiac causes of sudden death in athletes are; hypertrophic cardiomyopathy, cardiac conduction problems, coronary artery anomalies, cardiac arrest due to severe blows to the chest and upper respiratory tract infection may be considered as carditis. ${ }^{22}$ Hypertrophic cardiomyopathy (36\%), coronary anomalies (19\%) and cardiac mass increase $(10 \%)$ were found in the top three in a study that investigated sudden deaths in 158 competing athletes in the United States between 1985 and $1995 .{ }^{23}$

Both the American Heart Association (AHA) and the European Cardiology Association (ESC) panel recommendations agreed that young competing athletes should be screened for cardiac exposure. ${ }^{24,25}$ However, there are differences in screening methods. While AHA recommends a complete medical history and family history with physical examination, ESC recommends the routine use of a 12-lead ECG in the initial screening. ${ }^{26}$

Hypertrophic cardiomyopathy or right ventricular cardiomyopathy shows various ECG changes, including straight or deeply inverted $\mathrm{T}$ waves and deep $\mathrm{Q}$ waves (including a dramatic increase in $\mathrm{R}$ or $\mathrm{S}$ wave voltage) indicating the presence of structural cardiovascular disease. In a study conducted with 1005 individuals from 38 different sports branches comparing ECG with echocardiography, $40 \%$ of the participants had abnormal ECG findings and $5 \%$ had structural heart problems. ${ }^{27}$

In our study, ECG findings were interpreted pathologically in 4 people $(2.2 \%)$; one person had delta wave, two had right bundle branch block (one with axial deviation), and one had short QTc. It appears that the pathological ECGs interpreted as belonging to men. This may be due to the fact that most of the participants $(81.8 \%)$ are men. On the other hand, it has been considered that male gender is a risk factor in itself for sudden cardiac death. ${ }^{22}$ However, it was understood that these findings did not predict the important pathologies that would prevent the individuals from continuing their sports life.

There are different applications for screening methods. The main reason for this difference is the variability in cost approach. According to a study conducted in the USA in 2012, the cost of more than $\$ 10$ million is saved in every case where sudden death is prevented by ECG. ${ }^{28}$ In the same study, it is strangely argued that ECG is a financial burden on the US economy and may hinder the implementation of some methods that can be used to prevent cardiac death. In addition, according to another study led by Italian researchers, a screening program in which ECG will not be used will be both more expensive and insufficient to identify heart disease. ${ }^{29}$ It is thought that this difference in opinion on cost effectiveness depends on different structuring of health systems. In this regard, the health system in terms of cost-effectiveness of screening with ECG in Turkey closer to European Union countries that have been evaluated would be more useful.

The existence of family medicine practice in our country can be used as a great advantage in this respect. From birth to death, it will be very easy for a family physician to monitor and record at least one ECG record for participation in sports to a person with records. In addition, 12-lead ECG is not widely used and interpretable in our country. It is considered that it would be beneficial to take measures to eliminate the lack of education in this regard.

It will be necessary to interpret this research with some limitations. First, the age range of athletes is distributed over a wide range. The possibility of such a wide range of influences should be kept in mind. On the other hand, muscle building protein contents, anabolic steroids that athletes may use are not considered. In addition, the lack of examination and laboratory data of athletes before starting sports can be considered a limitation.

\section{CONCLUSION}

The presence of conditions that may pose a risk to the health of athletes in people who are engaged in active sports suggests that some findings have been missed in the examinations for entry to sports. This research 
shows that health screening is important for the health of the athlete, although a health report is obtained to start sports in the current practice, some pathologies can be omitted, on the other hand, only anamnesis and physical examination may not be sufficient to determine the health problems and basic laboratory tests should be performed. Based on this research, a national guide for sports entry examinations and screening of athletes should be developed with larger sample and multi-center studies.

\section{ACKNOWLEDGEMENTS}

All of the contributors during the research are included in the article authors. This work has not been funded by any organization.

\section{DISCLOSURE}

There is no conflict of interest of the authors in this study. This article is produced from the Medical Specialty thesis.

\section{REFERENCES}

1. Warburton DER, Nicol CW, Bredin SSD. Health benefits of physical activity: the evidence. Cmaj. 2006;174:801-9. PubMed ID: 16534088 doi: 10.1503/cmaj.051351

2. Çelik A, Şahin M. Spor ve Çocuk Gelişimi. Int J Soc Sci.2013;6:467-78.

3. Fonseca-Junior SJ, Sa CGA de B, Rodrigues PAF, Oliveira AJ, Fernandes-Filho J. Physical exercise and morbid obesity: a systematic review. Arq Bras Cir Dig. 2013;26 Suppl 1:67-73. PubMed ID: 24463903 doi: 10.1590/s0102-67202013000600015

4. Friedenreich CM. Physical activity and breast cancer: review of the epidemiologic evidence and biologic mechanisms. Recent Results Cancer Res. 2011;188:125-39. PubMed ID: 21253795 doi: 10.1007/978-3-64210858-7_11

5. Brown JC, Winters-Stone K, Lee A, Schmitz KH. Cancer, physical activity, and exercise. Compr Physiol. 2012;2:2775-809. PubMed ID: 23720265 doi:10.1002/cphy.c120005

6. Liu Y, Hu F, Li D, et al. Does physical activity reduce the risk of prostate cancer? A systematic review and meta-analysis. Eur Urol.2011;60:1029-44. PubMed ID: 21802197 doi:10.1016/j.eururo.2011.07.007

7. Bozhüyük A, Özcan S, Kurdak H, Akpınar E, Saatçı E, Bozdemir N. Sağlıklı yaşam biçimi ve aile hekimliği. Turkish J Fam Med Prim Care. 2012;6:88-92.

8. Harris AHS, Cronkite R, Moos R. Physical activity, exercise coping, and depression in a 10-year cohort study of depressed patients. J Affect Disord. 2006;93:79-85. PubMed ID: 16545873 doi: 10.1016/j.jad.2006.02.013

9. Aucella F, Valente GL, Catizone L. The role of physical activity in the CKD setting. Kidney Blood Press Res. 2014;39:97-106. PubMed ID: 25117619 doi:10.1159/000355783.

10. Moreira LDF, Oliveira ML de, Lirani-Galvao AP, Marin-Mio RV, Santos RN dos, Lazaretti-Castro M. Physical exercise and osteoporosis: effects of different types of exercises on bone and physical function of postmenopausal women. Arq Bras Endocrinol Metabol.2014;58:514-22. PubMed ID: 25166042 doi: 10.1590/0004-2730000003374

11. Busch AJ, Schachter CL, Overend TJ, Peloso PM, Barber KAR. Exercise for fibromyalgia: a systematic review. J Rheumatol.2008;35:1130-44. PubMed ID: 18464301

12. Krell-Roesch J, Feder NT, Roberts RO, et al. Leisure-Time Physical Activity and the Risk of Incident Dementia: The Mayo Clinic Study of Aging. J Alzheimers Dis. 2018;63:149-55. PubMed ID: 29614667 doi:10.3233/JAD-171141 
13. Maron BJ, Haas TS, Doerer JJ, Thompson PD, Hodges JS. Comparison of U.S. and Italian experiences with sudden cardiac deaths in young competitive athletes and implications for preparticipation screening strategies. Am J Cardiol. 2009;104:276-80. PubMed ID: 19576360 doi:10.1016/j.amjcard.2009.03.037

14. Açar B, Kara M. Review Article / Derleme Sudden Cardiac Death in Athletes : Current Approaches in Clinical Practice Sporcularda Ani Kardiyak Olum : Klinik Pratikte Guncel Yaklaşımlar. Turkish J Sport Med. 2017;52. doi:10.5152/tjsm.2017.002

15. Harmon KG, Asif IM, Klossner D, Drezner JA. Incidence of sudden cardiac death in National Collegiate Athletic Association athletes.Circulation. 2011;123:1594-600. PubMed ID: 21464047 doi:10.1161/CIRCULATIONAHA.110.004622.

16. von Elm E, Altman DG, Egger M, et al. The Strengthening the Reporting of Observational Studies in Epidemiology (STROBE) statement: guildelines for reporting observational studies. J Clin Epidemiol. 2008;61:344-9. PubMed ID: 18313558 doi: 10.1016/j.jclinepi.2007.11.008

17. Lenth R. Java Applets for Power and Sample Size [Computer software] 2009. https://homepage.divms.uiowa.edu/ rlenth/Power/ (accessed May 24, 2018).

18. Lehman PJ, Carl RL. The Preparticipation Physical Evaluation.Pediatr Ann. 2017;46:e85-92. PubMed ID: 28287681 doi:10.3928/19382359-20170222-01

19. Aktürk Z, Acemoğlu H, Işık M, Akçay F. Sağlık Çalışanları İçin Araştırma ve Pratik İstatistik Örnek Problemler ve SPSS Çözümleri. 3rd ed. İstanbul: Anadolu Matbaası; 2015.

20. Farzam K, Akhondi H. Sports Participation Evaluation. Treasure Island (FL): StatPearls Publishing; 2019. PubMed ID: 30969510

21. Vorona E, Nieschlag E. Adverse effects of doping with anabolic androgenic steroids in competitive athletics, recreational sports and bodybuilding. Minerva Endocrinol. 2018;43:476-88. PubMed ID: 29463075 doi:10.23736/S0391-1977.18.02810-9

22. Wasfy MM, Hutter AM, Weiner RB. Sudden Cardiac Death in Athletes.Methodist Debakey Cardiovasc J . 2016;12:76-80. PubMed ID: 27486488 doi:10.14797/mdcj-12-2-76

23. Maron BJ, Shirani J, Poliac LC, Mathenge R, Roberts WC, Mueller FO. Sudden death in young competitive athletes. Clinical, demographic, and pathological profiles. JAMA. 1996;276:199-204. PubMed ID: 8667563

24. Maron BJ, Levine BD, Washington RL, Baggish AL, Kovacs RJ, Maron MS. Eligibility and Disqualification Recommendations for Competitive Athletes With Cardiovascular Abnormalities: Task Force 2: Preparticipation Screening for Cardiovascular Disease in Competitive Athletes: A Scientific Statement From the American Heart Associ. J Am Coll Cardiol. 2015;66:2356-61. PubMed ID: 26542659 doi:10.1016/j.jacc.2015.09.034

25. Corrado D, Pelliccia A, Bjornstad HH, et al. Cardiovascular pre-participation screening ofyoung competitive athletes for prevention of sudden death: proposal for a common Europeanprotocol. Consensus Statement of the Study Group of Sport Cardiology of the Working Group of Cardiac Rehabilitation and. Eur Heart J. 2005;26:516-24. PubMed ID: 15689345 doi:10.1093/eurheartj/ehi108

26. Dhutia H, MacLachlan H. Cardiac Screening of Young Athletes: a Practical Approach to Sudden Cardiac Death Prevention. Curr Treat Options Cardiovasc Med. 2018;20:85. PubMed ID: 30155696 doi: 10.1007/s11936-018-0681-4

27. Pelliccia A, Maron BJ. Athlete's heart electrocardiogram mimicking hypertrophic cardiomyopathy. Curr Cardiol Rep. 2001;3:147-51. PubMed ID: 11177673 doi: 10.1007/s11886-001-0042-9

28. Schoenbaum M, Denchev P, Vitiello B, Kaltman JR. Economic evaluation of strategies to reduce sudden 
cardiac death in young athletes.Pediatrics. 2012;130:e380-9. PubMed ID: 22753553 doi:10.1542/peds.20113241

29. Assanelli D, Levaggi R, Carre F, et al. Cost-effectiveness of pre-participation screening of athletes with ECG in Europe and Algeria.Intern Emerg Med. 2015;10:143-50. PubMed ID: 25164412 doi: 10.1007/s11739014-1123-2

Table 1. Descriptive information of the participants.

\begin{tabular}{lllll}
\hline & Min & Max & Mean & SD \\
\hline QTc (msn) & 330 & 453 & 392,55 & 21,94 \\
QRS (ms) & 64 & 121 & 85,31 & 10,14 \\
PR (msn) & 86 & 200 & 133,02 & 17,50 \\
Sport time (years) & 1 & 8 & 2,71 & 1,07 \\
Length (cm) & 130 & 187 & 169,82 & 8,11 \\
Weight (kg) & 35 & 98 & 67,93 & 11,65 \\
Body Mass Index (kg / m2) & 17,06 & 32,45 & 23,43 & 3,00 \\
Systolic blood pressure (mmHg) & 80 & 130 & 102,63 & 12,07 \\
Diastolic blood pressure (mmHg) & 50 & 82 & 65,45 & 8,30 \\
Cardiac Speed (min) & 58 & 92 & 72,15 & 7,46 \\
Hemoglobin (g / dl) & 10 & 18,1 & 14,31 & 1,62 \\
Number of white spheres (mm3) & 4000 & 14000 & 7171,99 & 1667,39 \\
Platelets (mm3) & 120000 & 540000 & 257668 & 59480 \\
Glucose (mg / dL) & 66 & 134 & 87,61 & 7,84 \\
BUN (mg / dl) & 6 & 20 & 12,01 & 2,80 \\
Creatinine (mg / dL) & 0,4 & 1 & 0,78 & 0,15 \\
AST (IU / L) & 11 & 39 & 20,07 & 4,43 \\
SUB (IU / L) & 9 & 52 & 18,32 & 6,53 \\
Na (mmol / L) & 132 & 145 & 139,69 & 2,54 \\
K (mmol / L) & 4 & 5,2 & 4,64 & 0,43 \\
Ca (mg / dl) & 8 & 10,3 & 9,40 & 0,56 \\
Triglyceride (mg / dL) & 39 & 330 & 93,92 & 39,94 \\
LDL (mg / dL) & 30 & 187 & 86,41 & 23,65 \\
HDL (mg / dL) & 29 & 74 & 47,06 & 8,79 \\
TSH (mU / L) & 0,9 & 7 & 2,32 & 0,85 \\
ST4 (ng / dl) & 0,9 & 1,7 & 1,09 & 0,15 \\
\hline
\end{tabular}

SD: Standart deviation.

Table 2. Distribution of participants according to their sport

\begin{tabular}{lll}
\hline & $\mathrm{n}$ & $\%$ \\
\hline Football & 30 & 16,60 \\
Volleyball & 22 & 12,20 \\
Swimming & 21 & 11,60 \\
Athletics & 14 & 7,70 \\
Shooting & 12 & 6,60 \\
Canoe & 12 & 6,60 \\
Tae-kwon-do & 10 & 5,50 \\
Basketball & 10 & 5,50
\end{tabular}




\begin{tabular}{lll}
\hline & $\mathrm{n}$ & $\%$ \\
\hline Karate & 10 & 5,50 \\
Boxing & 10 & 5,50 \\
Wrestle & 10 & 5,50 \\
Barbell & 10 & 5,50 \\
Ping pong & 10 & 5,50 \\
Total & 181 & 100,00 \\
\hline
\end{tabular}

Table 3. Comparison of age, anthropometric, biochemistry and ECG measurement results.

\begin{tabular}{|c|c|c|c|c|c|c|}
\hline Variables & Result of evaluation & $\mathbf{n}$ & Mean & SD & $\mathrm{t} / \mathrm{Z}$ & $\mathbf{p}$ \\
\hline \multirow[t]{2}{*}{ Age (year) } & No pathology & 156 & 21,12 & 6,31 & $-0,554$ & 0,584 \\
\hline & Pathology & 25 & 22,16 & 9,02 & & \\
\hline \multirow[t]{2}{*}{ QRS (msn) } & No pathology & 156 & 84,92 & 10,01 & $-1,282$ & 0,201 \\
\hline & Pathology & 25 & 87,72 & 10,85 & & \\
\hline \multirow[t]{2}{*}{ Training (gün/hafta) } & No pathology & 156 & 2,42 & 0,45 & $-2,961$ & 0,006 \\
\hline & Pathology & 25 & 2,72 & 0,50 & & \\
\hline \multirow[t]{2}{*}{ Length $(\mathrm{Cm})$} & No pathology & 156 & 169,79 & 8,43 & $-0,886$ & 0,144 \\
\hline & Pathology & 25 & 170,04 & 5,84 & & \\
\hline \multirow[t]{2}{*}{ Weight (Kg) } & No pathology & 156 & 67,27 & 11,32 & $-1,915$ & 0,057 \\
\hline & Pathology & 25 & 72,04 & 13,07 & & \\
\hline \multirow[t]{2}{*}{ BMI } & No pathology & 156 & 23,20 & 2,71 & $-1,942$ & 0,063 \\
\hline & Pathology & 25 & 24,88 & 4,19 & & \\
\hline \multirow[t]{2}{*}{ Systolic Blood Pressure } & No pathology & 156 & 101,9 & 11,27 & $-1,624$ & 0,115 \\
\hline & Pathology & 25 & 107,2 & 15,68 & & \\
\hline \multirow[t]{2}{*}{ Diastolic Blood Pressure } & No pathology & 156 & 64,91 & 8,27 & $-2,199$ & 0,029 \\
\hline & Pathology & 25 & 68,8 & 7,81 & & \\
\hline \multirow[t]{2}{*}{ White Blood Cell } & No pathology & 156 & 7189,68 & 1726,78 & 0,356 & 0,722 \\
\hline & Pathology & 25 & 7061,6 & 1256,72 & & \\
\hline \multirow[t]{2}{*}{ Platelets } & No pathology & 156 & 256512,8 & 57716,49 & $-0,652$ & $0,654^{*}$ \\
\hline & Pathology & 25 & 264880 & 70412,67 & & \\
\hline \multirow[t]{2}{*}{ This } & No pathology & 156 & 12,14 & 2,83 & 1,567 & 0,119 \\
\hline & Pathology & 25 & 11,2 & 2,48 & & \\
\hline \multirow[t]{2}{*}{ Creatinine } & No pathology & 156 & 0,778 & 0,15 & 0,554 & 0,581 \\
\hline & Pathology & 25 & 0,76 & 0,14 & & \\
\hline \multirow[t]{2}{*}{ AST } & No pathology & 156 & 19,94 & 4,51 & $-0,982$ & 0,327 \\
\hline & Pathology & 25 & 20,88 & 3,90 & & \\
\hline \multirow[t]{2}{*}{ ALT } & No pathology & 156 & 17,59 & 5,73 & $-3,294$ & $0,001 *$ \\
\hline & Pathology & 25 & 22,88 & 9,12 & & \\
\hline \multirow[t]{2}{*}{$\mathrm{Na}$} & No pathology & 156 & 139,63 & 2,57 & $-0,826$ & 0,410 \\
\hline & Pathology & 25 & 140,08 & 2,36 & & \\
\hline \multirow[t]{2}{*}{$\mathrm{K}$} & No pathology & 156 & 4,624 & 0,43 & $-0,951$ & 0,343 \\
\hline & Pathology & 25 & 4,712 & 0,40 & & \\
\hline \multirow[t]{2}{*}{$\mathrm{Ca}$} & No pathology & 156 & 9,362 & 0,54 & $-2,390$ & 0,018 \\
\hline & Pathology & 25 & 9,644 & 0,60 & & \\
\hline \multirow{2}{*}{ LDL } & No pathology & 156 & 81,12 & 16,84 & $-5,802$ & $<0,001^{*}$ \\
\hline & Pathology & 25 & 119,44 & 32,33 & & \\
\hline \multirow[t]{2}{*}{ HDL } & No pathology & 156 & 47,86 & 8,80 & 3,665 & 0,001 \\
\hline & Pathology & 25 & 42,08 & 7,05 & & \\
\hline
\end{tabular}




\begin{tabular}{lllllll}
\hline Variables & Result of evaluation & $\mathbf{n}$ & Mean & SD & t/Z & $\mathbf{p}$ \\
\hline sT4 & No pathology & 156 & 1,086 & 0,15 & $-0,192$ & 0,848 \\
& Pathology & 25 & 1,092 & 0,15 & & \\
Cardiac Speed & No pathology & 156 & 71,38 & 7,46 & $-4,428$ & $<\mathbf{0 , 0 0 1}$ \\
& Pathology & 25 & 76,92 & 5,49 & & \\
\hline
\end{tabular}

*Mann witney U testi.

Table 4. Comparison of categorical variables according to results

\begin{tabular}{|c|c|c|c|}
\hline & & Examination of pathology & Examin \\
\hline & & No exist & No exis \\
\hline Variables & Variables & $\mathbf{n}$ & $\%$ \\
\hline \multirow{2}{*}{ Sex } & Erkek & 127 & 85,81 \\
\hline & Kadın & 29 & 87,88 \\
\hline \multirow{2}{*}{ Delta wave } & No Exist & 155 & 86,11 \\
\hline & Exist & 1 & 100,00 \\
\hline \multirow[t]{2}{*}{ Right bundle branch block } & No Exist & 155 & 86,59 \\
\hline & Exist & 1 & 50,00 \\
\hline \multirow[t]{2}{*}{ General ECG review } & Normal & 153 & 86,44 \\
\hline & Pathological & 3 & 75,00 \\
\hline \multirow[t]{3}{*}{ Axis } & Normal & 155 & 86,59 \\
\hline & Right Axis & 1 & 100,00 \\
\hline & Left Axis & 0 & 0,00 \\
\hline \multirow[t]{2}{*}{$\mathrm{T}$ wave } & Normal & 156 & 86,67 \\
\hline & Pathological & 0 & 0,00 \\
\hline \multirow[t]{2}{*}{ Ventricular hypertrophy } & No Exist & 156 & 86,67 \\
\hline & Exist & 0 & 0,00 \\
\hline \multirow[t]{2}{*}{ During or after exercise dizziness, blackout, fainting } & No Exist & 150 & 86,21 \\
\hline & Exist & 6 & 85,71 \\
\hline \multirow[t]{2}{*}{ During or after exercise chest pain or shortness of breath } & No Exist & 138 & 85,71 \\
\hline & Exist & 18 & 90,00 \\
\hline \multirow[t]{2}{*}{ Fatigue during exercise, before friends } & No Exist & 129 & 87,16 \\
\hline & Exist & 27 & 81,82 \\
\hline \multirow[t]{2}{*}{ Different or fast heart beats while resting } & No Exist & 145 & 86,31 \\
\hline & Exist & 11 & 84,62 \\
\hline \multirow[t]{2}{*}{ Death due to heart disease before the age of 50 in the family } & No Exist & 155 & 86,59 \\
\hline & Exist & 1 & 50,00 \\
\hline \multirow[t]{2}{*}{ Family history of sudden death of unknown cause at a young age } & No Exist & 154 & 86,03 \\
\hline & Exist & 2 & 100,00 \\
\hline
\end{tabular}

